\title{
Experimental investigation of Priming Technique of Centrifugal Pump using Vacuum for Mobile Water Purification System
}

\author{
Manish Bhati ${ }^{1}$, T R Meena ${ }^{2}$, Mahendra $\operatorname{singh}^{3}$, Deepesh Patidar $^{4}$, Dr. Prashant Vasistha ${ }^{5}$, \\ Ravindra Kumar ${ }^{6}$, Swapnil Umredkar ${ }^{7}$ \\ ${ }^{1,4,5,6}$ Scientist, Defence Lab, Jodhpur \\ ${ }^{2}$ Technical Officer, Defence lab, Jodhpur \\ ${ }^{3}$ Technician, Defence lab, Jodhpur \\ ${ }^{7}$ Research Intern, Student, G.H. Raisoni College of Engineering, Nagpur
}

\begin{abstract}
This paper deals with the feasibility study and comparison of vacuum based and gravity based priming techniques for centrifugal pump. In this paper, the experiments are performed to study the particulars of Vacuum based priming setup, for use in mobile Water Purification system(WPS). The setup was prepared in a manner to inculcate the use and efficiency by considering the factors like maximum height to be achieved, time analysis to estimate the time needed to completely fill the suction line and pump cavity. For gravity based priming techniques a stored water is necessary but in critical or emergency situation like war zone and flooded area mobile WPS system has to be established and stored water is not always available. In order to make it suitable for mobile use vacuum based priming technique for centrifugal pump is investigated.
\end{abstract}

Keywords- Vacuum based Priming, Gravity priming, Vacuum pump, Mobility, priming, water purification

\section{I- INTRODUCTION}

$\mathbf{P}$ riming is an essential step for smooth start of the centrifugal pumps. But on the contrary, basic priming methods like gravity-based priming does not work in every situation like in emergency call like war-prone areas, floods, etc where time available for plant start is limited. In such areas, alternate priming techniques, other than gravity priming, might be more effective. New methods have to be adopted in order to get ready for any situation. Vacuum based priming can be an efficient way for mobile systems' pump priming. In order to study the feasibility of vacuum based priming system, full scale experiments were performed and the feasibility is derived accordingly.

\subsection{Centrifugal Pump}

A centrifugal pump is a type of roto dynamic pump, which consists of rotating impeller which in turn increases the flow rate and pressure of a fluid. The fluid 


\section{International Journal of Innovations in Engineering and Science, www.ijies.net}

enters the pump impeller along to the rotating axis and further it is accelerated by the impeller, which is flowing radially outward or axially into the volute chamber or diffuser, from where the fluid exits into the downstream piping system. Centrifugal pumps are typically used or practiced for large discharge through smaller heads. The term "centrifugal pump" describes all impeller type rotodynamic pumps including the axial, radial and mixed-flow variations. Every industry today requires a pump somewhere in its operation to carry out certain process. Pipes do carry the fluid, but pumps are responsible to supply the energy in order to move it. As the piping and pumps work together, they must be thought of and should be designed as an integrated system. The parameters like elbow, valve, inside diameters of all equipment, length of pipe, the height of the pump above or below the reservoir, and fluid viscosity affect the optimal discharge flow for the system.

\subsection{Pump material}

Pump material can be of Stainless steel (SS 316 or SS 304), cast iron, aluminium etc. These types of materials are used because they can withstand harsh conditions. It depends upon the application of pump. In water industry and for pharma applications, SS 316 is in use generally. As at high temperature stainless steel offers better result.

\subsection{Centrifugal Pump Priming}

Mostly the centrifugal pumps are not self-priming, they are to be primed before using. In other words, the pump casing should be filled with liquid before the pump is about to get started. If the pump casing gets filled with vapors or gases, the pump impeller becomes gas-bound and certainly incapable of pumping. To ensure that a centrifugal pump remains primed and it does not become gas-bound, most centrifugal pumps are located below the level of the source from which the pump is to take its suction so as to naturally practice the gravity-based priming. The same effect can be gained by supplying liquid to the pump suction under pressure supplied by another pump placed in the suction line.

Priming is done by using (i) a foot valve placed to hold the water in the pump (ii) by using an auxiliary piston pump to fill the pump (iii) placing connection to an outside source of water under pressure in order to fill the pumps and (iv) by the use of a self-priming construction. Self-Priming Pumps are a design of centrifugal pumps which use an air-water mixture to reach a fully-primed pumping condition. By using fluid left in a reservoir, the impeller forces out the air from the casing, which in turn creates a vacuum and suction that primes the pump. The advantage is that the pump can stay in areas that are dry and easy to access for maintenance.

The ability of a pump to self-prime can be affected by several factors, the discharge line must not be pressurized or blocked. The suction line should be air tight. Volume of the suction side pipe line should be minimum to reduce priming time. With excessive priming time there is a danger that the liquid charge will evaporate before priming and dry running may damage the pump. In cold environment if water freeze inside the pump it may damage the pump or pipe.

\section{II-LITERATURE SURVEY}

Indian patent 279575 "An auto priming centrifugal pump" describes about a system in which there is no requirement of electricity and is engine driven. This invention utilizes a vacuum pump, which is mounted on the main drive shaft or drive by the belt pulley arrangement. The vacuum pump remove air in the pump casing as well as suction pipe and creates partial vacuum in the casing and suction side. (1)

US Patent about "Vacuum priming system for centrifugal pimps" (US Patent 5536147). This invention utilized separate vacuum pump to suck water to fill suction line and impeller of the centrifugal pump. Once the impeller filled, a control valve connects the vacuum pump to the atmosphere. The invention also utilized level sensing switches and solenoid operated control valves to protect the vacuum pump to be flooded. (2)

US Patent 6071072 "Self priming centrifugal pump" having a trapping mechanism which traps a part of liquid and uses the same for priming in next operation. It also introduces air separation unit to repeated utilization of trapped liquid. This invention is not suitable for mobile applications due to leakage of trapped liquid during movement. (3)

US patent 5795127 "Vertical shaft "self-priming" centrifugal pump" in which a semi flooded inlet and semi open impeller is required and cannot be used in applications where the pump has to be installed at a level higher than the liquid level. (4)

\section{III-CAD MODEL AND PROCESS FLOW PLANNING}

In order to setup the system for priming of centrifugal pumps the module was decided and the CAD model (Fig-1) was designed by using Licensed PTC CREO 3D CAD Modelling Software. Model was finalized after minor changes and the setup was installed as per the 


\section{International Journal of Innovations in Engineering and Science, www.ijies.net}

requirements to test the priming process of centrifugal pumps by using oil ring vacuum pump of $1 \mathrm{HP}$ rating.

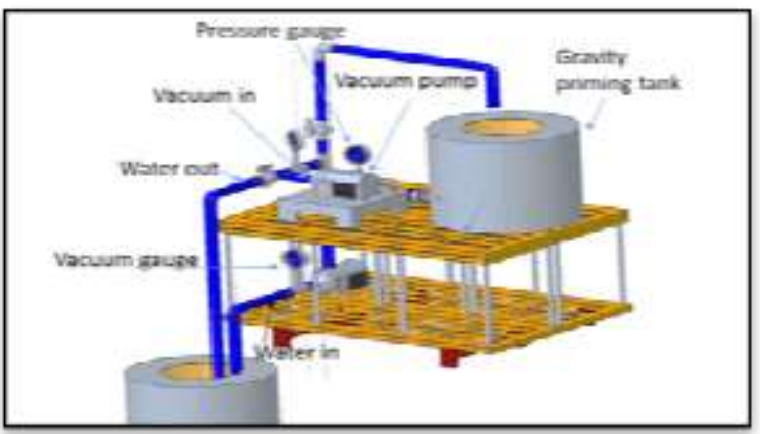

Fig 1-3D CAD Model of Proposed Setup

The flow diagram was planned for the priming process for both gravity and vacuum based priming system. In the gravity based priming system (Fig-2) the necessary factor is that the priming tank and the piping system should be at the higher level than the centrifugal pump so that the fluid can easily flow to the volute chamber of centrifugal pump for priming.

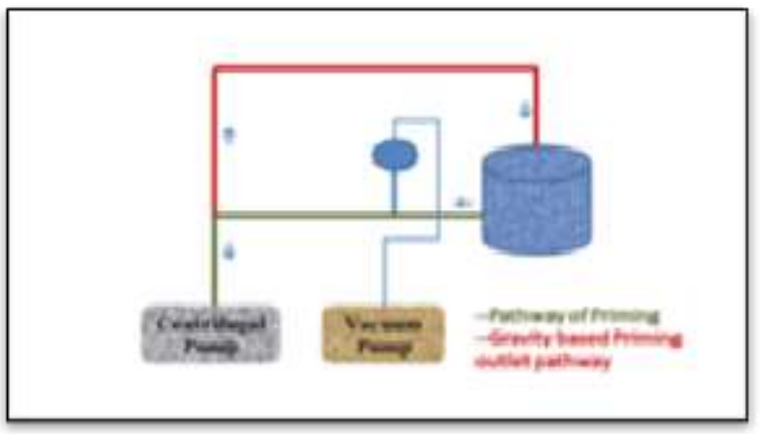

Fig 2- Flow diagram of Gravity based System

In vacuum based priming flow diagram (Fig-3) the moisture trapper was installed in order to resist the fluid to enter into vacuum oil ring pump, as if the fluid enters the vacuum pump it can damage the oil ring.

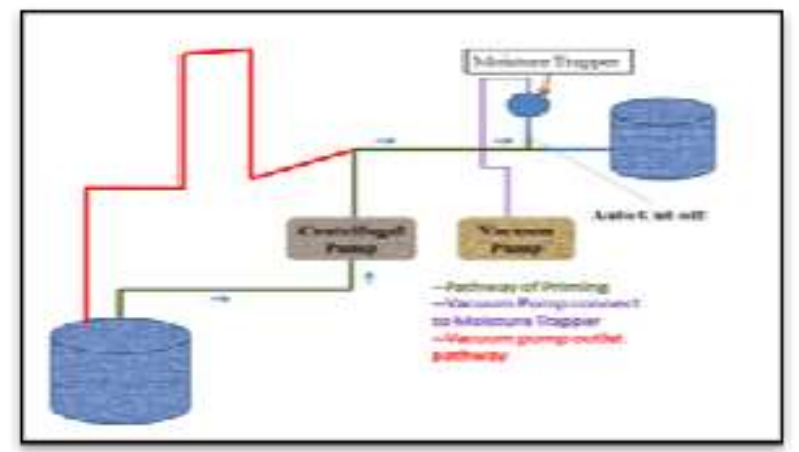

Fig 3 - Flow diagram of Vacuum based Priming

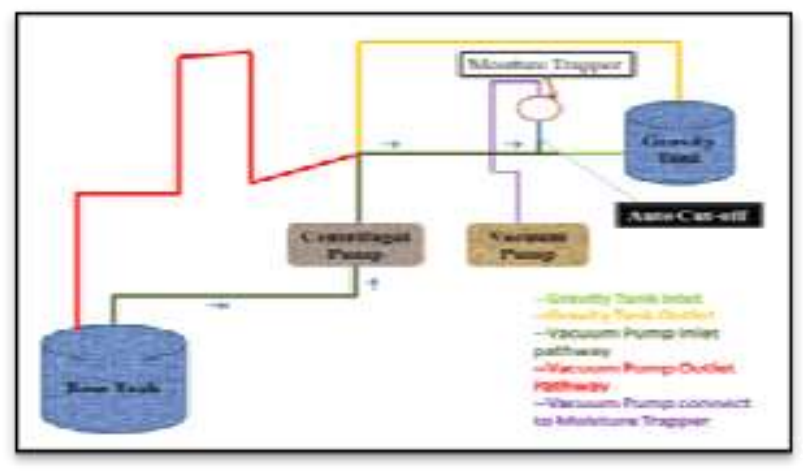

Fig 4 -Flow diagram of planned entire system (Gravity \& Vacuum)

Both gravity and vacuum based priming flow diagram was finalized (Fig-4) and accordingly experiments were planned.

\section{IV- EQUIPMENT USED IN EXPERIMENTS}

4.1 Centrifugal pump (Fig-5):

- Make: Grundfos

- Type: CH8-30 A-W-G-BOQV

- Model: D 46518030 A10751

- Pressure:10 bar

- Q: $7.5 \mathrm{~m}^{3} / \mathrm{hr}$

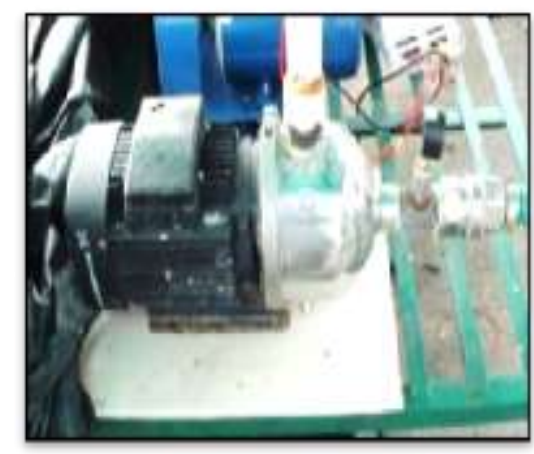

Fig 5- Centrifugal Pump

4.2 Vacuum Pump (Fig-6):

- Make: Prominent

- Model: PV-300 (Oil ring)

- Cap: 300 lpm (Free air displacement)

- Rpm: 1440

- HP: 1 HP 


\section{International Journal of Innovations in Engineering and Science, www.ijies.net}

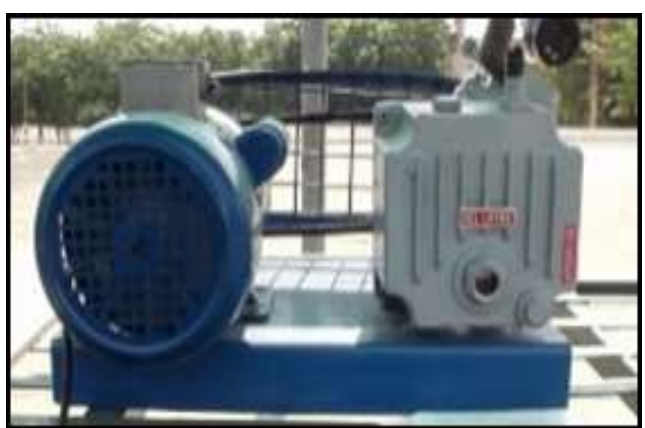

Fig 6- Vacuum Pump
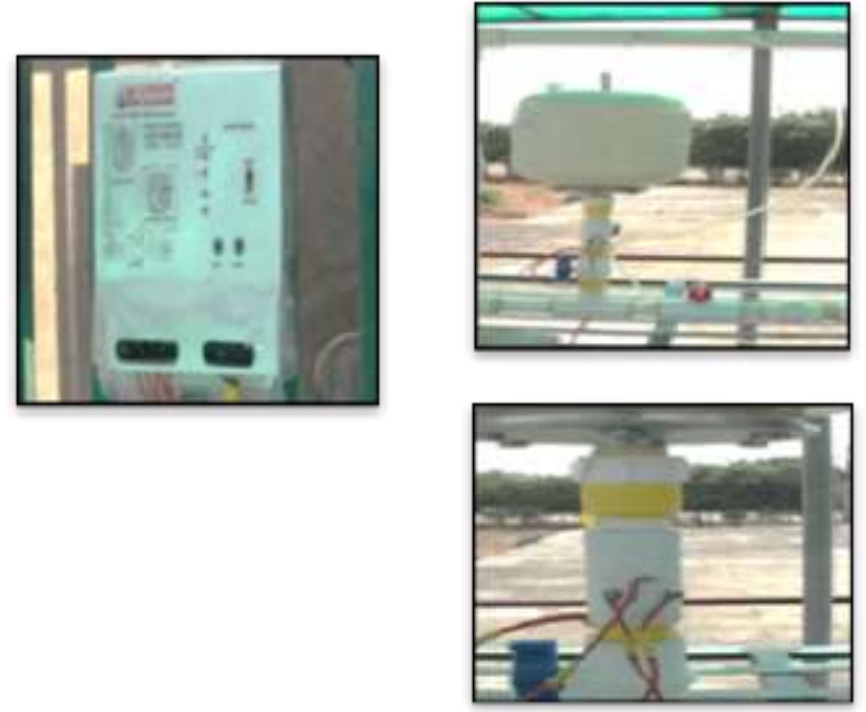

Fig 7- Auto Cut OFF System

\subsection{Auto cut-off system:}

Liquid level controller (LLC Type-II, Fig-7) was used in auto cut off mode to break the circuit and cut off the supply in order to stop the vacuum pump as soon as the water level is reached as planned. Moisture trapper was installed to avoid the entrance of water droplets in the vacuum oil ring pump.

\subsection{Supporting items are listed in table no 1}

Table 1: Supporting Equipment used in experiment

\begin{tabular}{|c|c|c|c|c|c|}
\hline $\begin{array}{l}\mathrm{Sr} \\
\mathrm{No}\end{array}$ & Equipment list & Company & Specification & Material & Quantity \\
\hline 1 & Gravity Tank & Sintex & Capacity: 200 litres & - & 1 \\
\hline 2 & Base Tank & Sintex & Capacity: 2000 litres & - & 1 \\
\hline 3 & Inlet rigid Pipes & Finolex & $\begin{array}{l}\text { 48.26mm; OD- 1-1/2’'; } \\
\text { ASTM D } 1785 \text { SCHD } 80\end{array}$ & CPVC & $\begin{array}{l}\text { AS PER } \\
\text { REQUIRE } \\
\text { MENT }\end{array}$ \\
\hline 4 & Outlet rigid Pipes & Finolex & $\begin{array}{l}33.40 \text { mm; OD- 1'’; } \\
\text { ASTM D } 1785 \text { SCHD } 40\end{array}$ & CPVC & $\begin{array}{l}\text { AS PER } \\
\text { REQUIRE } \\
\text { MENT }\end{array}$ \\
\hline 5 & Ball valve & Finolex & 1-1/2"; 1.0MPa & CPVC & 3 \\
\hline 6 & $\mathrm{~T}$ joints & Finolex & $\begin{array}{l}\text { 1-1/2"x90; ASTM D } 2467 \text { SCH-80 } \\
\text { 1-1/2”x90x1”; ASTM D } 2467 \text { SCH-80 } \\
1-1 / 2 ” \times 90^{\circ} \times 1 / 2 ” \text { ASTM D } 2467 \text { SCH-80 }\end{array}$ & CPVC & $\begin{array}{l}2 \\
1 \\
2\end{array}$ \\
\hline 7 & Elbow joints & $\begin{array}{l}\text { Finolex } \\
\text { Marcos }\end{array}$ & $\begin{array}{l}\text { 1-1/2”x90 ; ASTM D } 2467 \text { SCH-80 } \\
\text { 1-1/2”x1”; ASTM D } 2461 \text { SCH-80 } \\
\text { 1"; ASTM D } 2467 \text { SCH-80 }\end{array}$ & CPVC & $\begin{array}{l}2 \\
1 \\
2\end{array}$ \\
\hline 8 & Pressure gauge & Akari & $\begin{array}{l}\text { Range: } \\
0-10 \mathrm{kgf} / \mathrm{cm}^{2} \\
0-150 \mathrm{psi}\end{array}$ & - & 1 \\
\hline 9 & Vacuum gauge & Manometer & $\begin{array}{l}\text { Range:0-30 inHg } \\
0-760 \mathrm{mmHg}\end{array}$ & - & 3 \\
\hline 10 & Rotameter & Asina & Range: 0-6000 LPH & - & 1 \\
\hline 11 & Liquid level controller & Ajwin & Type: LLC 2 & - & 1 \\
\hline 12 & $\begin{array}{l}\text { Green flexible suction } \\
\& \text { delivery hose pipe }\end{array}$ & Polyplast & 1-1/2"; Bursting pressure $16 \mathrm{~kg} / \mathrm{cm}^{2}$ & PVC & 1 \\
\hline
\end{tabular}




\section{International Journal of Innovations in Engineering and Science, www.ijies.net}

\section{Calculation of maximum suction lift by using a vacuum pump:}

The concept behind lifting up the water is that when a pump creates a suction/ lowers the pressure in its suction port the atmospheric pressure pushes the water or fluid up the suction pipe. Thus the water flows from an area of high pressure to low pressure. This pressure difference uplifts the water up the suction hose. Under ideal conditions theoretically the maximum height that can be achieved is $10.34 \mathrm{~m}$. That's the height where the weight of atmosphere pushing the water up the hose gets equal to the weight of water in the hose. As we know that in real-world or in practical conditions pumps are incapable of producing a perfect vacuum, realistic limit of $7 \mathrm{~m}$ or $8 \mathrm{~m}$ can be considered. This is the point wherein weight of water in the hose gets equals to force from the difference between atmospheric pressure and the lessthan-perfect vacuum the pump is producing.

Maximum possible suction lift can be calculated as: (Ideal conditions)

Atmospheric pressure at sea level $=14.7 \mathrm{psi}=1.034$ $\mathrm{kg} / \mathrm{cm}^{2}$ (effectively the weight of atmosphere acting every square centimeter of the water's surface)

Vacuum pressure inside sealed tube $=0 \mathrm{psi}=0 \mathrm{~kg} / \mathrm{cm}^{2}$ (perfect vacuum)

Weight of $1 \mathrm{~cm} 3$ of water $=0.001 \mathrm{~kg}$

"(Atmospheric (atm) pressure - Vacuum Pressure) / Weight of water"

$\left(1.034 \mathrm{~kg} / \mathrm{cm}^{2}-0 \mathrm{~kg} / \mathrm{cm}^{2}\right) / 0.001 \mathrm{~kg}=1034 \mathrm{~cm}=$ $10.34 \mathrm{~m}$

Maximum possible suction lift can be calculated as: (Practical conditions)

Atmospheric pressure at the sea level $=14.7 \mathrm{psi}=1.034$ $\mathrm{kg} / \mathrm{cm} 2$ (effectively weight of atmosphere acting at every square centimeter of the water's surface)

Partial Vacuum pressure inside tube practically attainable $=4 \mathrm{psi}=0.2812 \mathrm{~kg} / \mathrm{cm} 2$ (realistic amount a vacuum pump can produce)

Weight of $1 \mathrm{~cm} 3$ of water $=0.001 \mathrm{~kg}$

"(Atmospheric (atm) pressure - Vacuum Pressure) / Weight of water"

$(1.034 \mathrm{~kg} / \mathrm{cm} 2-0.2812 \mathrm{~kg} / \mathrm{cm} 2) / 0.001 \mathrm{~kg}=752 \mathrm{~cm}=$ $7.52 \mathrm{~m}$

\section{Volume of the pathway followed by Vacuum} based priming

The total volume of the pathway followed by the vacuum based priming system was calculated by the formula: Volume $=\pi r^{2} l$
Where,

$\mathrm{r}=$ radius of the pipe; $1=$ length of the pipe

The total volume comes out to be $13013 \mathrm{~cm}^{3}$ (i.e. 13.013 litres) with the height of 5.28 metres

\section{Experimental Plan and Setup Installation}

Experiments were planned in order to derive or estimate the time taken by the vacuum oil ring pump to prime centrifugal pump and in order to study the advantages of vacuum based priming over gravity-based priming in certain aspects. The items used are listed in Table-1. Experiments were planned with following objectives:

(a) Pump capacity estimation

(b) Effect of vacuum on priming time taken;

(c) Comparison with respect to space occupied;

(d) Comparison with respect to Operational ease Note: While performing this experiment the inlet green suction pipe used was an "year-old" pipe

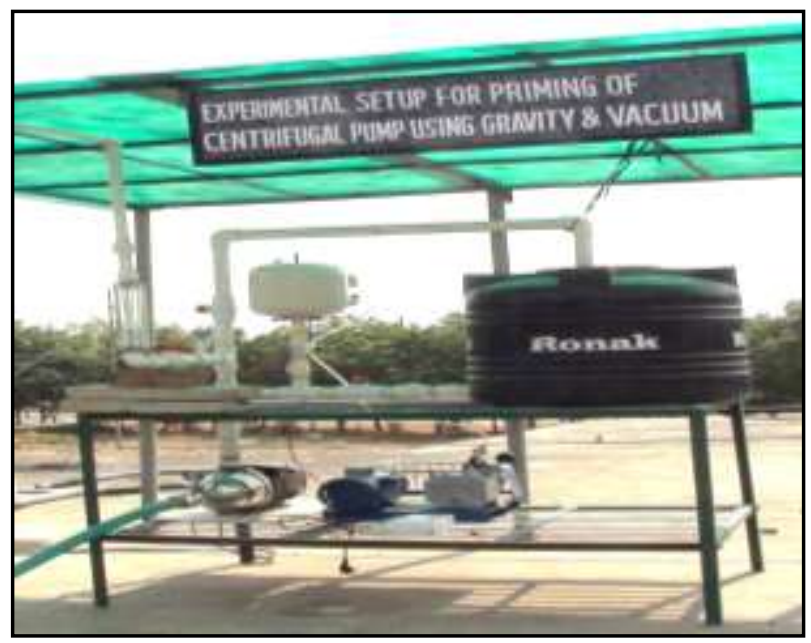

Fig 8 - Full Scale Experimental Setup

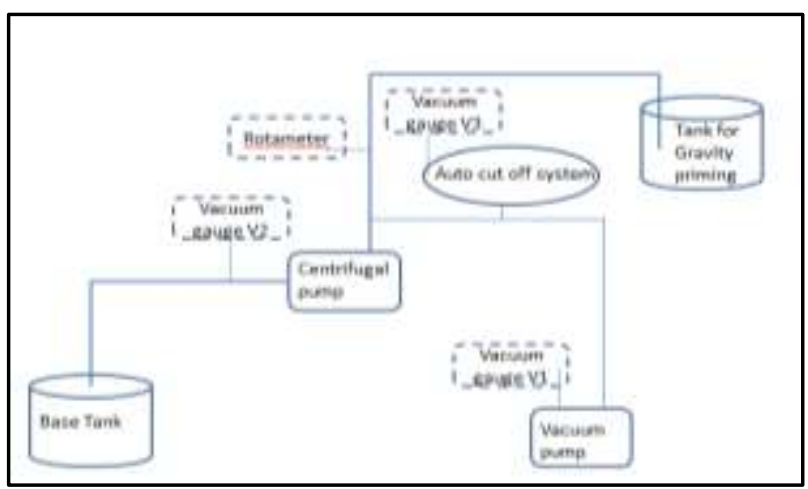

Fig 9- Layout of sub components

7. Experiment No 1(a) Pump capacity estimation at different operating pressure 


\section{International Journal of Innovations in Engineering and Science, www.ijies.net}

The centrifugal system was primed by using vacuum pump and the centrifugal pump (Fig-8) was switched ON in order to check the flow rate using rotameter. Experiment was performed by turning the ball valve lever at particular angle and measuring the pressure and flow rate to observe the smooth functionality of the centrifugal pump. The travel of the ball valve lever is from $0^{\circ}$ to $90^{\circ}$. The observations are detailed in Table- 2 .

Table 2-Experiment no 1 (a) observations

\begin{tabular}{|l|l|l|l|l|l|l|}
\hline $\begin{array}{l}\text { Sr } \\
\text { no }\end{array}$ & $\begin{array}{l}\text { V1 } \\
(\mathrm{mmh} \\
\mathrm{g})\end{array}$ & $\begin{array}{l}\text { Ball } \\
\text { valve } \\
\text { angle } \\
\left(0-90^{0}\right)\end{array}$ & \multicolumn{2}{|l|}{$\begin{array}{l}\text { Pressure } \\
\text { Gauge }(\mathrm{psi})\end{array}$} & $\begin{array}{l}\text { Rotameter } \\
(\text { Flow } \\
(\text { LPH })\end{array}$ \\
\hline & & & $\begin{array}{l}\text { Exp } \\
1\end{array}$ & $\begin{array}{l}\text { Exp } \\
2\end{array}$ & Exp 1 & Exp 2 \\
\hline 1 & 450 & 90 & 5 & 5 & 4850 & 4900 \\
\hline 2 & 450 & 60 & 10 & 12 & 4600 & 4700 \\
\hline 3 & 450 & 30 & 40 & 35 & 3400 & 3500 \\
\hline
\end{tabular}

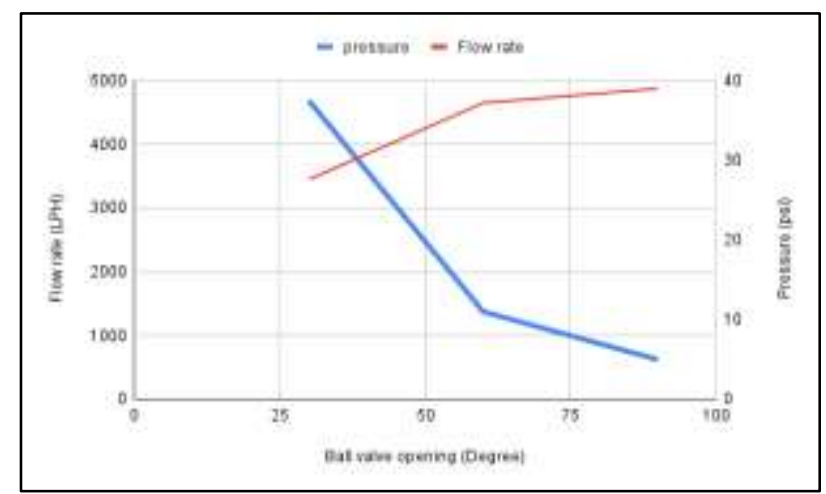

Fig 10 - Graphical analysis of experiment 1(a)

\section{Experiment No 1(b): Vacuum level V/S Cut off time}

Experiment was performed in order to get the estimation for the time taken by the vacuum pump to lift the water from 5.28 metres depth.

The vacuum was configured by adjusting the valve of the vacuum pump and considering the set vacuum as base for the remaining values as shown in the Table-3. Cut off time was also recorded.

Table 3-Experiment no 1 (b) observations

\begin{tabular}{|l|l|l|l|l|l|l|}
\hline $\begin{array}{l}\text { Sr } \\
\text { no }\end{array}$ & $\begin{array}{l}\text { V1 } \\
(\mathrm{mm} \\
\mathrm{Hg})\end{array}$ & $\begin{array}{l}\text { Cut- } \\
\text { off } \\
\text { Time } \\
(\mathrm{s})\end{array}$ & $\begin{array}{l}\text { Cut- } \\
\text { off } \\
\text { Time } \\
(\mathrm{s})\end{array}$ & $\begin{array}{l}\text { Cut- } \\
\text { off } \\
\text { Time } \\
(\mathrm{s})\end{array}$ & $\begin{array}{l}\text { Cut- } \\
\text { off } \\
\text { Time } \\
(\mathrm{s})\end{array}$ & $\begin{array}{l}\text { Cut- } \\
\text { off } \\
\text { Time } \\
(\mathrm{s})\end{array}$ \\
\hline 1 & 250 & 37.94 & 50.54 & 46.12 & 47.41 & 45.5 \\
\hline
\end{tabular}

\begin{tabular}{|l|l|l|l|l|l|l|}
\hline 2 & 300 & 31.69 & 33.75 & 36.41 & 36.34 & 37.47 \\
\hline 3 & 350 & 29.09 & 32.47 & 33.03 & 32.75 & 33.41 \\
\hline 4 & 400 & 29.44 & 31.25 & 30.78 & 31.18 & 31.5 \\
\hline 5 & 450 & 28.07 & 30.57 & 30.04 & 29.56 & 30.72 \\
\hline
\end{tabular}
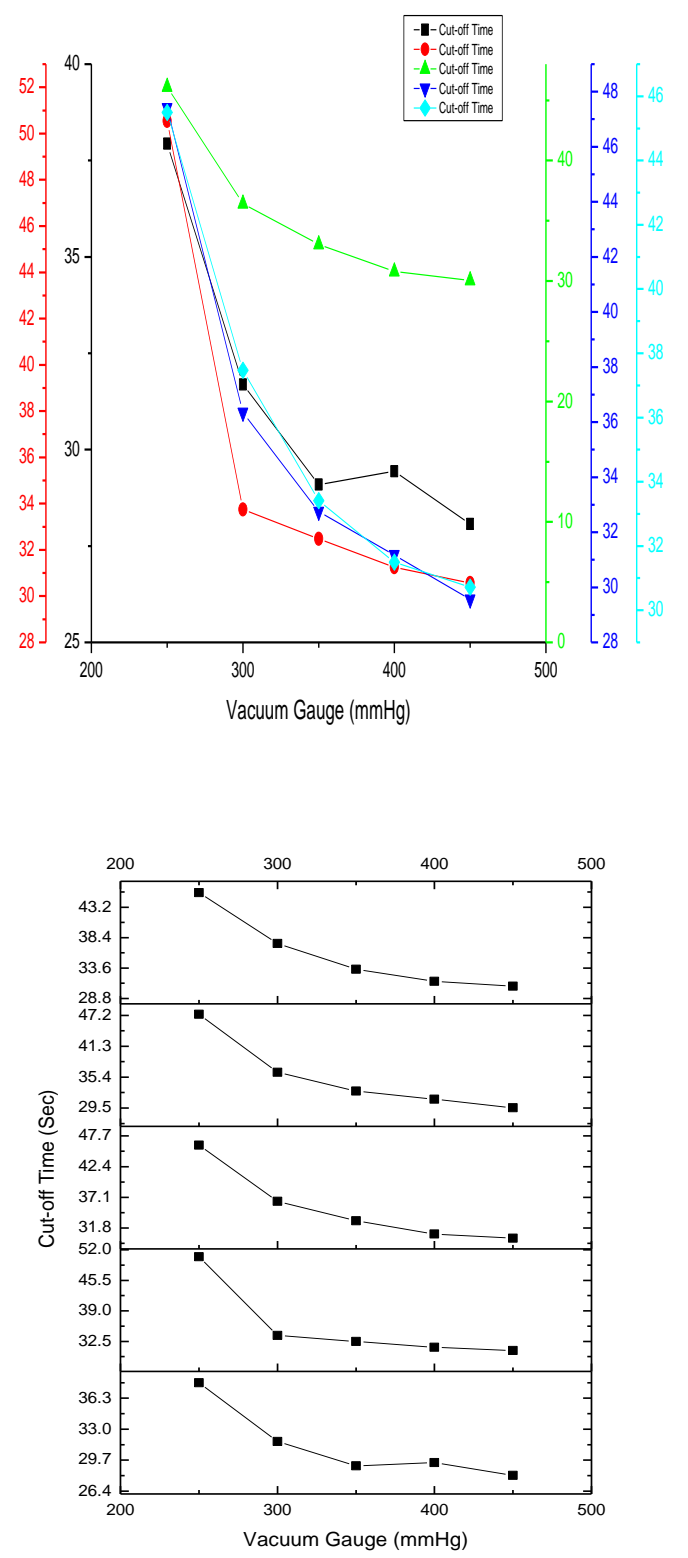

Fig 11 - Graphical analysis of experiment 1(b)

\section{Experiment No 1(c): Vacuum level V/S Vacuum value at Centrifugal pump inlet}

Experiments were performed to find out the vacuum produced at centrifugal pump inlet for a particular value of vacuum generated by vacuum pump. The vacuum was configured by adjusting the valve and considering the set vacuum as base for the remaining values as shown in the table-4. Cut off time was recorded for the instances. 
International Journal of Innovations in Engineering and Science, www.ijies.net

Table 4- Experiment no 1 (c) observations

\begin{tabular}{|l|l|l|l|}
\hline $\begin{array}{l}\text { Sr } \\
\text { No }\end{array}$ & $\begin{array}{l}\text { Vacuum V1 } \\
\text { (at Vacuum } \\
\text { pump), } \\
\mathrm{mmHg}\end{array}$ & $\begin{array}{l}\text { Vacuum V2 } \\
\text { (Centrifugal } \\
\text { pump inlet), } \\
\mathrm{mmHg}\end{array}$ & $\begin{array}{l}\text { Cut-off } \\
\text { Time (sec) }\end{array}$ \\
\hline 1 & 250 & 315 & 49.00 \\
\hline 2 & 275 & 315 & 41.03 \\
\hline 3 & 300 & 330 & 37.59 \\
\hline 4 & 325 & 335 & 35.16 \\
\hline 5 & 350 & 340 & 34.63 \\
\hline 6 & 375 & 350 & 32.88 \\
\hline 7 & 400 & 350 & 32.5 \\
\hline 8 & 425 & 365 & 31.19 \\
\hline 9 & 450 & 365 & 30.28 \\
\hline
\end{tabular}
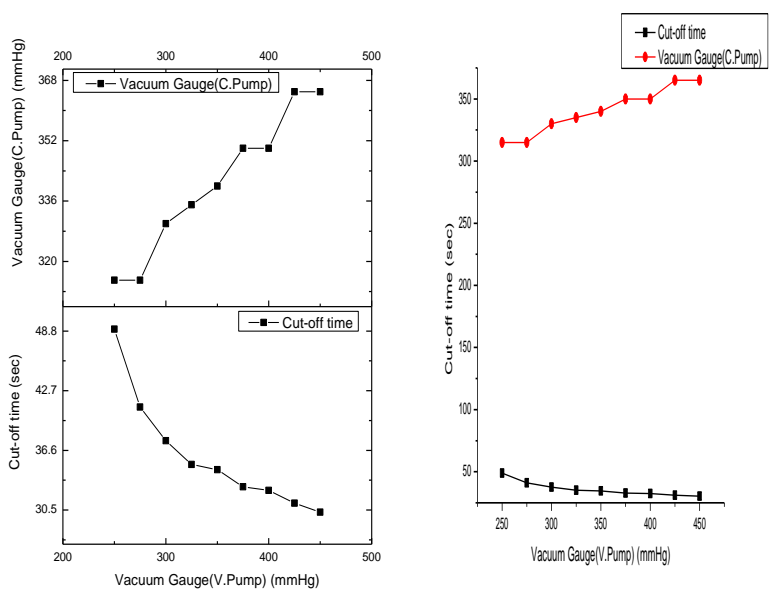

Table 5- Experiment no 1(C2) Observations

\begin{tabular}{|l|l|l|l|}
\hline Sr No & V1(mmhg) & V2 (mmhg) & $\begin{array}{l}\text { Cut-off Time } \\
(\mathrm{sec})\end{array}$ \\
\hline 1 & 250 & 310 & 38.66 \\
\hline 2 & 275 & 310 & 31.59 \\
\hline 3 & 300 & 320 & 30.65 \\
\hline 4 & 325 & 325 & 30.07 \\
\hline 5 & 350 & 320 & 29.66 \\
\hline 6 & 375 & 330 & 27.81 \\
\hline 7 & 400 & 340 & 26.72 \\
\hline 8 & 425 & 335 & 26.38 \\
\hline 9 & 450 & 335 & 26.10 \\
\hline
\end{tabular}
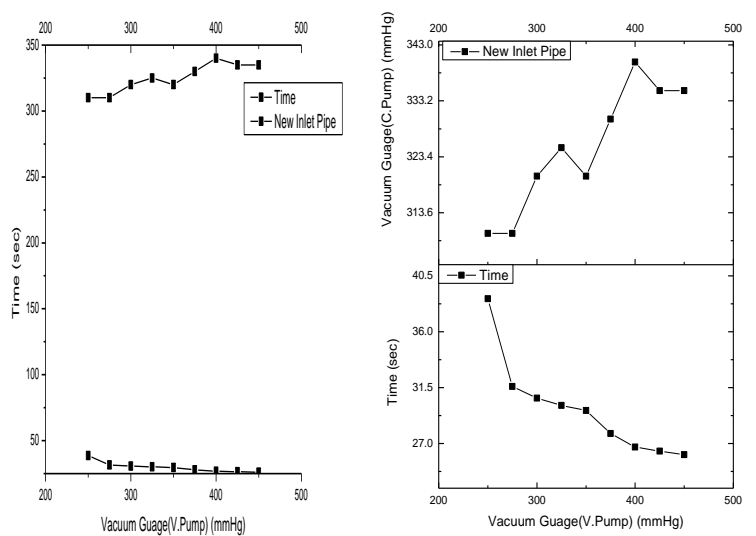

Fig 12 - Graphical analysis of experiment 1(C2)

10. Experiment No 1(d): Vacuum at moisture trapper setup:

Experiments were performed to compare the values of vacuum at centrifugal pump inlet and at moisture trapper. The valve of the vacuum was adjusted by vacuum pump valve and reading were taken (Table-6) at different locations. Cut off time were also recorded for the instances.

Table 6: Experiment no 1 (d) observations

\begin{tabular}{|l|l|l|l|l|}
\hline $\begin{array}{l}\text { Sr } \\
\text { No }\end{array}$ & $\begin{array}{l}\text { V1(Vacu } \\
\text { um } \\
\text { pump) } \\
\text { (mmhg) }\end{array}$ & $\begin{array}{l}\text { V3(Mois } \\
\text { ture } \\
\text { Trapper) } \\
\text { (mmhg) }\end{array}$ & $\begin{array}{l}\text { V2(Centrifu } \\
\text { gal pump } \\
\text { inlet) } \\
\text { Average } \\
\text { Value } \\
\text { (mmhg) }\end{array}$ & $\begin{array}{l}\text { Cut-off } \\
\text { Time } \\
\text { (sec) }\end{array}$ \\
\hline 1 & 250 & 375 & 300 & 40.19 \\
\hline 2 & 275 & 400 & 300 & 33.19 \\
\hline 3 & 300 & 390 & 310 & 29.28 \\
\hline 4 & 325 & 400 & 300 & 28.5 \\
\hline 5 & 350 & 395 & 310 & 27.88 \\
\hline 6 & 375 & 390 & 310 & 27.35 \\
\hline 7 & 400 & 390 & 300 & 26.91 \\
\hline 8 & 425 & 400 & 300 & 26.57 \\
\hline 9 & 450 & 390 & 310 & 25.94 \\
\hline
\end{tabular}




\section{International Journal of Innovations in Engineering and Science, www.ijies.net}
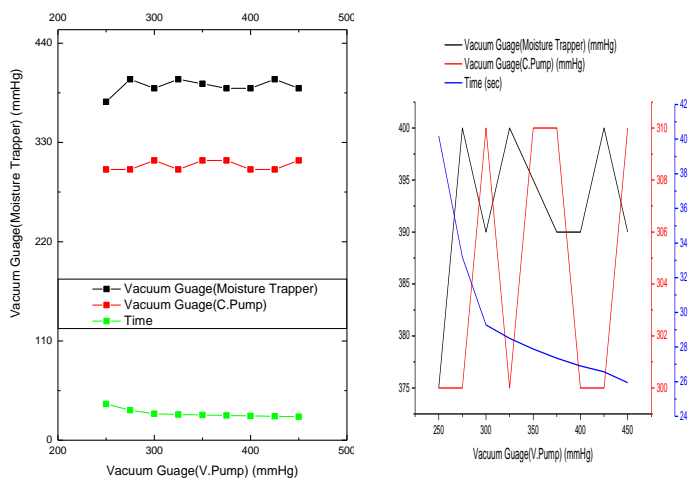

Fig 12 - Graphical analysis of $1(d)$

\section{Experiment No. 2: Comparison with respect to space occupied:}

As the system comprises of vacuum pump and moisture trapper for priming of centrifugal pump it can get accommodated inside 0.5 cubic metre volume or in even smaller volume easily as this setup does not need any tank preinstalled for priming purpose. In gravity based priming one has to have the source of water or fluid, that too at the higher level than the centrifugal pump to be primed, in order to attain smooth functionality. The water will not travel if there is no height difference and it will not be feasible if the source is not at the height than the pump. Herein, in the terms of space occupied the vacuum pump based priming system is more relevant and more feasible as they can be accommodated in less space than the gravity based priming setup.

\section{Experiment No.3: Comparison with respect to the use in a mobile system:}

For use in a mobile system the most simple and relevant system can be a vacuum based priming as it does not require any pre-stored water. It simply sucks the water from a water body at ground or lower level and fills the suction hose pipe as well as the pump volute. Thus this system is capable of priming the centrifugal pump from any of the available nearby source of water in emergency like war prone zone and in natural hazard conditions like floods, etc. Gravity based priming need a specific installation in order to carry out the priming as well as a minimum quantity of water stored in the priming tank installed at a higher height than the pump. Thus it is not feasible to use at every place or in emergency conditions.

13. Discussion: It can be seen that with increase in vacuum from $250 \mathrm{~mm} \mathrm{Hg}$ to $450 \mathrm{~mm} \mathrm{Hg}$ the priming time decreases from $45.5 \mathrm{~S}$ to $29.79 \mathrm{~S}$ as is noted in the table $3 \&$ fig 11 . There was variation in the vacuum level at vacuum pump, centrifugal pump and at moisture trapper setup as shown in experimental results of 1(c) and 1 (d). The variation in vacuum is attributed to the losses in the bends and through connecting pipe length along with some leakages in between. The final minimum vacuum available at the pump is $300 \mathrm{~mm} \mathrm{Hg}$ which is found to be sufficient for priming of feed pump from a depth of $5.28 \mathrm{~m}$.

\section{V- CONCLUSION}

The experiments were performed in order to study the feasibility of vacuum based priming system for certain parameters like the space required, suitability for a mobile system, estimation of time to uplift the water to find suitability of vacuum based priming system. Also the aim was to find its efficacy and relevance for priming of centrifugal pump. It can be concluded that the priming of centrifugal pump by using vacuum oil ring pump is more feasible, relevant, efficient and can be applicable for use in mobile water purification systems in case of any casualties or emergency field conditions. It can be concluded that to reach the height of 5.28metres with the total volume of 13.013 litres of water, the time that was required with highest vacuum of $450 \mathrm{mmh}$ is around 29 seconds using a year old suction pipe and around 26 seconds for new green suction pipe for priming of centrifugal pump. The flow rate was also observed in order to check the smooth functionality of centrifugal pump after priming operation was done and it was found suitable. In case of gravity based priming though it does not require any electric supply but it needs a preinstalled source or base tank with the base or source tank, installed at height above the centrifugal pump that is to be primed which makes it very difficult for the mobile use. The vacuum based priming system can be used in natural hazards, emergency situations like flood, etc with a very minimum setup or installation requirements and it is also feasible to accommodate the entire setup or the priming system in very small volume of around 0.5 cubic metre for the typical case considered.

\section{REFERENCES}

[1] Kirloskar Brothers Limited (2017), ,'An auto priming centrifugal pump”, Indian patent 279575

[2] David p. lang (1996), “Vacuum priming system for centrifugal pump”, US Patent 5536147

[3] Wante chang (2020), "Self priming centrifugal pump”, US Patent 6071072

[4] D Clark, David M (1994),"Vertical shaft selfpriming centrifugal pump" US patent 5795127 